Original Article

\title{
Development of a low-cost EMG biofeedback device kit as an educational tool for physical therapy students
}

\author{
Risa Suzuki, RPT, MMG' ${ }^{1,3)^{*}}$, Yoshihiro Muraoka, PhD ${ }^{1,2)}$, Shuntaro OKaZaki, $\mathrm{PhD}^{1,2)}$ \\ 1) Graduate School of Human Sciences, Waseda University: 2-579-15 Mikajima, Tokorozawa city, \\ Saitama 359-1192, Japan \\ 2) Department of Clinical Research, National Hospital Organization Murayama Medical Center, Japan \\ 3) Department of Health Science, Tokoha University, Japan
}

\begin{abstract}
Purpose] Electromyography biofeedback therapy is applied to various diseases during physical therapy for motor learning. Our aim was to develop a low-cost electromyography biofeedback device kit that students could build by themselves in class and to evaluate whether this kit was an adequate educational tool for physical therapy students. [Subjects and Methods] This study included 34 volunteers from a 3 year physical therapy vocational school and a 4 year university course. All students were tasked with: 1) completing a pre-questionnaire; 2) attending basic lectures on electromyography biofeedback therapy and how to build the device; 3) building the device; and 4) completing a post-questionnaire. [Results] Mean time required to build the device was $50.8 \pm 34.1$ minutes for the vocational course students and $27.4 \pm 8.8$ minutes for university students. For both groups, there was a significant increase in the number of students stating "have an interest in," "be involved with," and "have knowledge of electromyography biofeedback" when pre- and post-questionnaires were compared. In the post questionnaire, the frequency of the "knowledge increased" response was higher. [Conclusion] Physical therapy students can easily build our new device in a classroom, and this kit is a useful educational tool to motivate learning in electromyography biofeedback.

Key words: EMG-biofeedback, Education, Manufacturing
\end{abstract}

(This article was submitted May 15, 2017, and was accepted Jun. 2, 2017)

\section{INTRODUCTION}

Biofeedback is useful for learning how to control the body and is allied to rehabilitation for the recovery from paralysis or for strengthening muscle. To apply such biofeedback in physical therapy (PT), a variety of methods are available, including visual, auditory and electromyography-feedback technology. Video cameras are generally used for visual feedback, and the cost of such devices is currently affordable. However, EMG monitoring devices are not common, which means that few people are given the opportunity to gain essential knowledge pertaining to the use of EMG.

Electromyography biofeedback (EMG-BF) therapy is applied to a wide range of diseases, such as hemiplegia, orthopedic, peripheral neural diseases, during PT for motor learning ${ }^{1-4)}$. However, students in PT educational programs are given very limited opportunities to operate EMG-BF devices because of the high cost of this technology and insufficient number of devices available for training in the classroom. It is important for students to gain knowledge about this procedure because EMG-BF therapy has been included in the teaching tips of Japanese PT educational program curriculums, and questions regarding EMG-BF therapy are included in the national examination for a PT-registered license in Japan ${ }^{5}$.

The aim of this study was to develop a low-cost EMG-BF device kit that could be built by the students themselves within

*Corresponding author. Risa Suzuki (E-mail: risas@fuji.waseda.jp)

(C2017 The Society of Physical Therapy Science. Published by IPEC Inc.

(c) (1) $\odot$ This is an open-access article distributed under the terms of the Creative Commons Attribution Non-Commercial No Derivatives

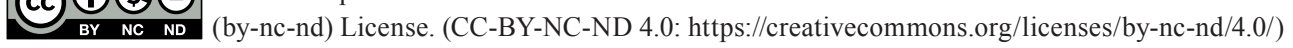


Table 1. General characteristics of the participants

\begin{tabular}{lcc}
\hline & 3-year students & 4-year students \\
& $(\mathrm{N}=16)$ & $(\mathrm{N}=18)$ \\
\hline Age (years) & $20.6 \pm 3.4$ & $20.9 \pm 0.6$ \\
Gender (male/female) & $7 / 9$ & $8 / 10$ \\
The percentage of the students who has soldering exeperience (\%) & 75.0 & 66.7 \\
\hline
\end{tabular}

an hour in class, to evaluate whether this device was an adequate educational tool for PT students, and identify methods for using this new device in the classroom.

\section{SUBJECTS AND METHODS}

First, a pre-experiment was conducted. The volunteer subjects used in this pre-experiment were 14 second-year students from a 3-year PT and Occupational Therapy vocational school $(\mathrm{N}=14$; mean age $=22.3 \pm 4.1$ years $)$. In this pre-experiment, we used Muraoka's low-cost EMG-BF device ${ }^{6}$ that can be connected to a smartphone and thus act as an EMG monitor. The students built the device on a breadboard in pairs. The mean time taken to complete building the device was $81.3 \pm$ 34.1 minutes (41-120 minutes). One pair gave up in their attempt to build the device. It was therefore considered possible that the device circuit was too difficult for the students to build themselves.

Then, in an attempt to make the kit easier to build, we changed some of the kits components such that there were fewer parts. The kit's components were as follows: a circuit breadboard base, a battery box, EMG pads, a terminal block-2 pin, log wires, 4-pole stereo conversion mini-plug, three alligator clips and connecting plug, two resistors (200 $\Omega$ ), an instrumentation amplifier (LT1167), a DC-DC converter (MAU106), two audio jacks, and two capacitors (10 $\mu \mathrm{F})$. The total cost of this device kit was approximately 15 dollars. The EMG amplifier had an additional AC coupling condenser in the output region of the circuit, as described by Muraoka et al. ${ }^{7)}$, which changed the amplification factor to 298. In the amplifier output, we installed an AC coupling condenser passive CR high-pass filter (cutoff frequency: $79.6 \mathrm{~Hz}$ ).

The volunteer subjects for the next experiment were 16 second-year students (mean age $=20.6 \pm 3.4$ years; seven males and nine females) from a 3 year PT vocational school and 18 second-year to fourth-year students (mean age $=20.9 \pm 0.6$ years; eight males and ten females) from a PT university. The proportion of students who had prior experience of soldering was $75.0 \%$ for the PT vocational school students and $66.7 \%$ for the PT university students (Table 1 ).

All subjects were asked to carry out the following procedure. First, they were asked to complete a pre-questionnaire assessing their response to several statements: "I have an interest in EMG-BF therapy," "I would like to be involved with EMG-BF therapy," "I can manage EMG-BF therapy," "I have knowledge of EMG-BF therapy," "My knowledge about EMG-BF therapy increased," "I acquired skills in EMG-BF therapy," "I am more interested in EMG-BF therapy," and "EMG-BF therapy is useful."

Second, students attended a basic lecture for 20 minutes regarding EMG-BF therapy and how to build the device. The lecture was presented using Microsoft PowerPoint, and students were given printed handouts.

Students were then asked to build the device in pairs. After the circuit was completed, it was connected to a smartphone to assess its function. We then calculated the mean length of time taken to complete building the device. After completing the device, the group of university students attempted to solder the circuit to universal substrate with a breadboard pattern.

Finally, students were asked to complete a post-questionnaire, which sought student responses to eight questions, which had been modified in accordance with the ministry's curriculum guidelines ${ }^{8)}$ : "I have an interest in EMG-BF therapy," "I would like to be involved with EMG-BF therapy," "I can manage EMG-BF therapy," "I have knowledge of EMG-BF therapy," "My knowledge of EMG-BF therapy has increased," "I acquired skills in EMG-BF therapy," "I am more interested in EMG-BF therapy," and "EMG-BF therapy is useful." For each question, responses were rated using the 5- Likert Scale from 1 ("I don't think so") to 5 ("think so much"). The first four questions (1-4) were the same as those on the pre-questionnaire. Using Statcel 2 (The Publisher OMS Ltd., Japan), a Wilcoxon test was then conducted to determine whether the pre- and post-questionnaire could explain the difference in students' attitudes toward EMG-biofeedback. Values of $\mathrm{p}<0.05$ were considered statistically significant. For questions 5-8, answers "scale-1" or "scale-2" were considered negative, "scale-3" was neither negative nor affirmative, and "scale-4" and "scale-5" were categorized as affirmative. The proportion (\%) of responses in each category was then calculated.

In addition, the 15 questions were modified in accordance with the motivational effects of an Attention, Relevance, Confidence, and Satisfaction (ARCS) motivation model ${ }^{9}$. The ARCS model represents a whole model of motivation and the effects on learning motivation consisting of four elements: attention, relevance, confidence, and satisfaction. This model enabled us to define which elements are important for learner motivation and to manage the design of our lesson effectively. The Japanese edition of this model ${ }^{10)}$ was validated and was considered reasonable for assessing student motivation. This present study uses the learning motivation assessment questionnaire created by Taniguchi ${ }^{11)}$ that was based on the ARCS model and was used to investigate the effect of our educational tool upon student motivation (Table 2). However, our current study did not include an evaluation of students; we therefore removed the last question from Taniguchi's questionnaire relat- 
Table 2. The questionnaire modified Taniguchi's learning motivation assessment

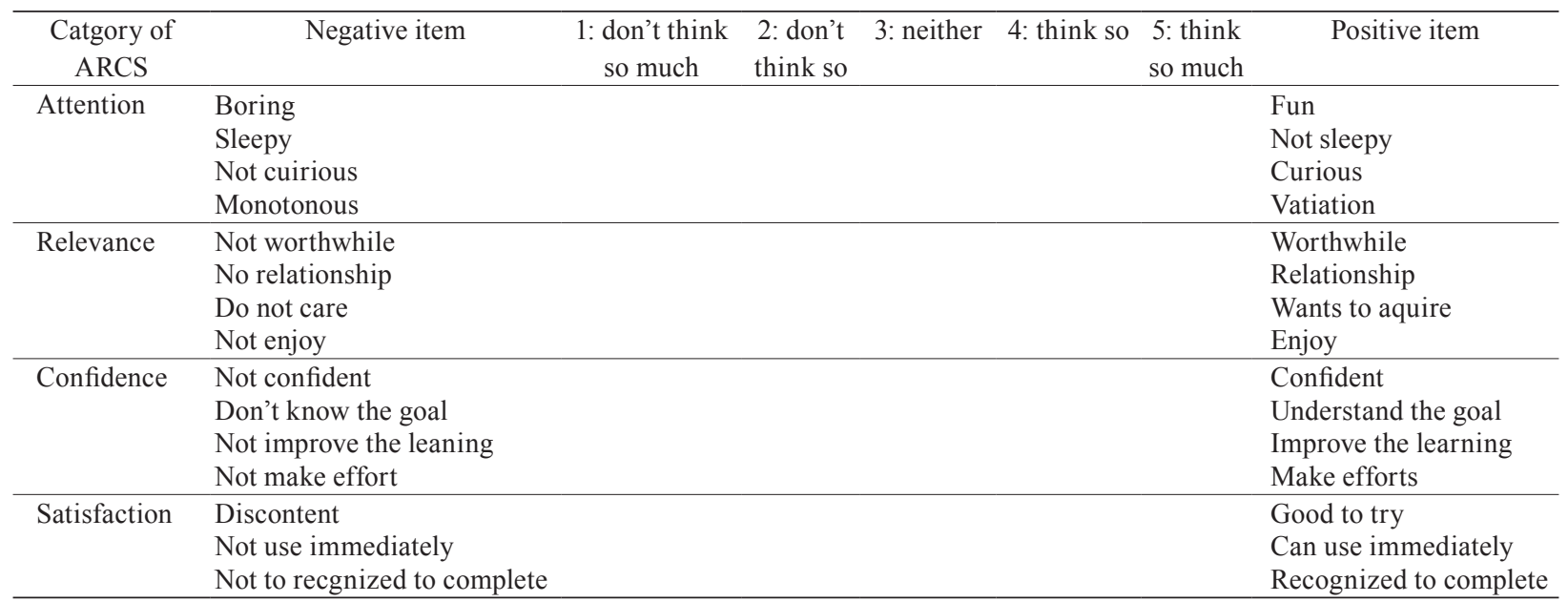

Table 3. Comparison of the result of pre-post questionaire about EMG-BF

\begin{tabular}{|c|c|c|c|c|}
\hline & \multicolumn{2}{|c|}{3 -year students $(\mathrm{N}=16)$} & \multicolumn{2}{|c|}{4 -year students $(\mathrm{N}=18)$} \\
\hline & Pre-questionaire & Post-questionaire & Pre-questionaire & Post-questionaire \\
\hline Have an interests (point) & $3.1 \pm 1.0$ & $3.8 \pm 0.9^{*}$ & $3.4 \pm 0.7$ & $4.1 \pm 0.4^{*}$ \\
\hline Involved in (point) & $2.8 \pm 0.6$ & $3.3 \pm 0.7^{*}$ & $3.3 \pm 0.6^{* *}$ & $3.8 \pm 0.6^{*}$ \\
\hline Can manage (point) & $2.3 \pm 1.1$ & $2.6 \pm 0.9$ & $1.7 \pm 1.0$ & $2.6 \pm 1.0^{*}$ \\
\hline Have knowledge of (point) & $1.4 \pm 0.6$ & $2.4 \pm 1.0^{*}$ & $1.3 \pm 0.7$ & $2.8 \pm 0.9^{*}$ \\
\hline
\end{tabular}

Values are mean \pm SD. Significantly different $(* p<0.05)$ between pre and post in the experimental group.

Significantly different $(* * \mathrm{p}<0.05)$ between three-year and four-year of pre-questionaire.

ing to satisfaction ("feel justice about the evaluation"). However, the "attention," "relevance," and "confidence" categories were included in four questions and "satisfaction" was included in three questions. The mean score for each category was calculated; a higher score indicated that the motivational effect was higher.

The Ethics Committee of Fuji rehabilitation institute (FUJ2016001) and Tokoha University (Kensei 16-8) approved this research study. There is no conflict of interest to declare. No sponsor had any control over the interpretation, writing, or publication of this research.

\section{RESULTS}

The mean time required to build the device was $50.8 \pm 34.1$ minutes (19-86 minutes) for the vocational school students and $27.4 \pm 8.8$ minutes (18-40 minutes) for the university students. All of the university students tried to solder the circuit because they had built the device faster, but none of these students were able to complete the soldering.

The vocational school students scores for "have an interest in," "be involved with," "have knowledge of" EMG-BF were significantly different $(\mathrm{p}=0.02, \mathrm{p}=0.02, \mathrm{p}=0.01)$ and the university students scores for "have an interests in," "be involved with," "can manage," "have knowledge of" EMG-BF were also significantly different ( $p=0.01, p=0.01, p=0.01, p=0.001$ ) when compared between pre- and post-questionnaires. The score for "be involved with" was significantly different between vocational school students and university students in the pre-questionnaires (Table 3).

The proportion of 3-year course students who answered affirmative to "knowledge increased" was $87.5 \%$, "acquired skill" was $68.8 \%$, "interesting" was $93.8 \%$, and "useful" was $93.8 \%$. The proportion of university students who answered affirmative to "knowledge increased" was $88.9 \%$, "acquired skill" was $55.6 \%$, "interesting" was $94.4 \%$, and "useful" was $77.8 \%$ (Table 4). The average ARCS scores for the vocational school students were $4.1 \pm 0.9$ for "attention," $4.2 \pm 0.7$ for "relevance," $3.7 \pm 0.9$ for "confidence," and $4.0 \pm 1.0$ for "satisfaction," while the university student scores were $4.2 \pm 0.9$ for "attention," $4.4 \pm 0.6$ for "relevance," $3.7 \pm 0.6$ for "confidence," and $3.7 \pm 0.8$ for "satisfaction," respectively (Table 5).

\section{DISCUSSION}

The mean time to complete and operate the device was within 60 minutes. The fastest time, for both groups, was within 20 minutes. Consequently, students can build the device themselves and a teacher can use this kit to teach students how to build the new EMG-BF device within the standard class time (90 minutes) in a Japanese university or vocational school. Using a 
Table 4. The result of post questionaire about EMG-BF

\begin{tabular}{llcc}
\hline & Answer & $\begin{array}{c}\text { 3-year students } \\
(\mathrm{N}=16)\end{array}$ & $\begin{array}{c}\text { 4-year students } \\
(\mathrm{N}=18)\end{array}$ \\
\hline Knowledge increased (\%) & Yes & 87.5 & 88.9 \\
& No & 6.3 & 0 \\
& Neither & 6.3 & 11.1 \\
\hline Acquired skill (\%) & Yes & 68.8 & 55.6 \\
& No & 6.3 & 0 \\
& Neither & 25 & 44.4 \\
\hline Interesting (\%) & Yes & 93.8 & 94.4 \\
& No & 0 & 0 \\
& Neither & 6.3 & 5.6 \\
\hline Useful (\%) & Yes & 93.8 & 77.8 \\
& No & 6.3 & 0 \\
& Neither & 0 & 22.2 \\
\hline
\end{tabular}

Table 5. Mean of ARCS category score

\begin{tabular}{lcc}
\hline & $\begin{array}{c}\text { 3-year students } \\
(\mathrm{N}=16)\end{array}$ & $\begin{array}{c}\text { 4-year students } \\
(\mathrm{N}=18)\end{array}$ \\
\hline Attention (point) & $4.1 \pm 0.9$ & $4.2 \pm 0.9$ \\
Relevance (point) & $4.2 \pm 0.7$ & $4.4 \pm 0.6$ \\
Confidence (point) & $3.7 \pm 0.9$ & $3.7 \pm 0.6$ \\
Satisfaction (point) & $4.0 \pm 1.0$ & $3.7 \pm 0.8$ \\
\hline
\end{tabular}

breadboard, students can build the device without soldering, and therefore, without professional knowledge of engineering, they can easily build the device kit without assistance. In this study, none of the university students were able to complete the soldering, even though most of them had soldering experience from junior high school. Consequently, soldering the circuit to a universal substrate with a breadboard pattern was believed to be too difficult for PT students. This means that if the PT students need to solder the circuit, then basic training is necessary on how to handle the soldering iron.

The frequency of student responses to "have an interest in," "be involved with," and "knowledge increased" was significantly higher in the post-questionnaire for both groups of PT students. This indicated that after using this educational tool, students were appreciative of EMG-BF methods and that this tool is useful for learning EMG-BF.

From the viewpoint of the ARCS model, the scores for "attention" and "relevance" were over 4-points in both groups of PT students. We found that actively building the device kit motivated students' curiosity and interest in EMG-BF. The "confidence" score was lower than the "attention" and "relevance" scores. Furthermore, the frequency of responses for "acquired skill" was lower than that for "knowledge increased" in both groups of students in the post-questionnaire. These responses suggested that the activity in this study helped students in acquiring knowledge on how to build the EMG-BF but not on how to use it sufficiently, although more than half of the students felt they had "acquired skill" throughout the activity. The frequency of responses to "be involved with" was significantly higher in the university PT students than in the vocational school PT students in the pre-questionnaires. This suggested higher pre-interventional motivation for using the EMG-BF for the university PT students than the vocational school PT students. Kawakami ${ }^{12)}$ showed that in a statics class, the ARCS score for "satisfaction" in university nursing students was lower than vocational nursing school students. Vocational school student were highly motivated toward their careers, and some had entered school following working experience. University students lacked some motivation for learning to some extent. This suggests that a special learning plan for university students might be required. In the present study, a lower score for "satisfaction" was evident in the university PT students than in the vocational school PT students. Thus, university students had more curiosity for new devices like EMG-BF, but they did not have much ability to link this to their future career; thus, their "satisfaction" score was lower than that of students from a vocational school. To motivate university PT students, it is now necessary to teach them how to use a EMG-BF device for therapeutic purposes in addition to building the device. This would allow them to link these educational experiences to a future career.

The limitation of the study is twofold. First, it is unclear whether our results for volunteers can also apply to general students who have less motivation or not. Second, we did not consider the effect of teacher's knowledge of engineering and her/his instruction ability on the time for the device completion. These limitations should be overcome to verify the universality of the device in future studies.

Since devices using EMG sensors, such as BF devices, myoelectric upper limb prosthesis, or rehabilitation robots, have become popular in clinical situations, the acquisition of knowledge relating to EMG has become very necessary for PT students. The educational tool proposed in this study familiarized PT students with EMG and provoked interest in the use of EMG. This effect will contribute toward furthering the motivation of PT students to use existing EMG devices and develop new EMG devices. 


\section{ACKNOWLEDGEMENT}

We wish to thank Shigeo Uchida for timely advice on recruiting volunteer students.

\section{REFERENCES}

1) Binder SA, Moll CB, Wolf SL: Evaluation of electromyographic biofeedback as an adjunct to therapeutic exercise in treating the lower extremities of hemiplegic patients. Phys Ther, 1981, 61: 886-893. [Medline] [CrossRef]

2) Holtermann A, Mork PJ, Andersen LL, et al.: The use of EMG biofeedback for learning of selective activation of intra-muscular parts within the serratus anterior muscle: a novel approach for rehabilitation of scapular muscle imbalance. J Electromyogr Kinesiol, 2010, 20: 359-365. [Medline] [CrossRef]

3) Middaugh S, Thomas KJ, Smith AR, et al.: EMG biofeedback and exercise for treatment of cervical and shoulder pain in individuals with a spinal cord injury: a pilot study. Top Spinal Cord Inj Rehabil, 2013, 19: 311-323. [Medline] [CrossRef]

4) Weatherall M: Biofeedback or pelvic floor muscle exercises for female genuine stress incontinence: a meta-analysis of trials identified in a systematic review. BJU Int, 1999, 83: 1015-1016. [Medline] [CrossRef]

5) Ministry of Health, Labor and Welfare: Scope of National Examination of Physical Therapist. http://www.mhlw.go.jp/file/06-Seisakujouhou-10800000-Iseikyoku/99.pdf (Accessed Apr. 10, 2017)

6) Muraoka Y, Ishio A, Takeda K: Low-cost 2ch EMG biofeedback device using a stereo microphone port. Jpn J Compr Rehabil Sci, 2014, 5: 1-6.

7) Muraoka Y: Development of low-cost electromyography feedback device by using a smartphone. Sogo Rehabil, 2014, 42: 161-164.

8) Ministry of Education, Culture, Sports, Science and Technology: Nature of learning of assessment of students. http://www.mext.go.jp/b_menu/shingi/chukyo/ chukyo3/004/gaiyou/attach/1292216.htm (Accessed Mar. 31, 2017)

9) Keller JM: Development and use of the ARCS model of instructional design. Journal of Instructional Development, 1987, 10: 2-10. [CrossRef]

10) Kawakami Y, Kougo C: Making an evaluation of the Japanese edition of Course Interest Survey Scale based on ARCS motivational model. Transactions of Japanese Society for Information and Systems in Education, 2013, 13: 289-294.

11) Taniguchi H, Yagi K, Kabeyama K: An approach to improve situation assessment using simulation learning methods, and the evaluation of midwifery students' learning motivation. Kyoto University Health Science, 2012, 7: $43-47$.

12) Kawakami Y: Differences in nursing students' motivation and attitudes towards statistics depending on educational background. J Jpn Soc Nurs Res, 2015, 38: $37-45$. 